\title{
Marginal Mandibular Branch of the Facial Nerve
}

National Cancer Institute

\section{Source}

National Cancer Institute. Marginal Mandibular Branch of the Facial Nerve. NCI

Thesaurus. Code C127834.

A branch of the facial nerve that innervates the musculature of the lower lip. 